University of Nebraska - Lincoln

DigitalCommons@University of Nebraska - Lincoln

Uniformed Services University of the Health

Sciences

U.S. Department of Defense

2011

\title{
Racial disparities in histopathologic characteristics of uterine cancer are present in older, not younger blacks in an equal-access environment
}

\author{
Kate E. Oliver \\ Walter Reed Army Medical Center \\ Lindsey R. Enewold \\ Walter Reed Army Medical Center \\ Kangmin Zhu \\ Uniformed Services University of the Health Sciences \\ Thomas P. Conrads \\ Women's Health Integrated Research Center at Inova Health System \\ G. Scott Rose \\ Walter Reed Army Medical Center \\ See next page for additional authors \\ Follow this and additional works at: https://digitalcommons.unl.edu/usuhs \\ Part of the Medicine and Health Sciences Commons
}

Oliver, Kate E.; Enewold, Lindsey R.; Zhu, Kangmin; Conrads, Thomas P.; Rose, G. Scott; Maxwell, G. Larry; and Farley, John J., "Racial disparities in histopathologic characteristics of uterine cancer are present in older, not younger blacks in an equal-access environment" (2011). Uniformed Services University of the Health Sciences. 48.

https://digitalcommons.unl.edu/usuhs/48

This Article is brought to you for free and open access by the U.S. Department of Defense at DigitalCommons@University of Nebraska - Lincoln. It has been accepted for inclusion in Uniformed Services University of the Health Sciences by an authorized administrator of DigitalCommons@University of Nebraska Lincoln. 


\section{Authors}

Kate E. Oliver, Lindsey R. Enewold, Kangmin Zhu, Thomas P. Conrads, G. Scott Rose, G. Larry Maxwell, and John J. Farley 


\title{
Racial disparities in histopathologic characteristics of uterine cancer are present in older, not younger blacks in an equal-access environment ${ }^{t}$
}

\author{
Kate E. Oliver ${ }^{\text {a }}$, Lindsey R. Enewold ${ }^{\mathrm{b}}$, Kangmin Zhu ${ }^{\mathrm{b}, \mathrm{c}}$, Thomas P. Conrads ${ }^{\mathrm{d}}$, G. Scott Rose ${ }^{\mathrm{a}}$, \\ G. Larry Maxwell a, John H. Farley ${ }^{\mathrm{e}, *}$ \\ a Division of Gynecologic Oncology, Department of Obstetrics and Gynecology, Walter Reed Army Medical Center, 6900 Georgia Avenue N.W., Washington, DC 20307, USA \\ b United States Military Cancer Institute, Walter Reed Army Medical Center, 6900 Georgia Avenue N.W., Washington, DC 20307, USA \\ c Department of Preventive Medicine and Biometrics, Uniformed Services University of the Health Sciences, 4301 Jones Bridge Road, Bethesda, MD 20814, USA \\ ' Gynecologic Cancer Center of Excellence, Women's Health Integrated Research Center at Inova Health System, 3289 Woodburn Road, Ste 375, Annandale, VA 22003, USA \\ e Department of Obstetrics and Gynecology, Uniformed Services University of the Health Sciences, 4301 Jones Bridge Road, Bethesda, MD 20814, USA
}

\section{A R T I C L E I N F O}

\section{Article history:}

Received 19 April 2011

Accepted 20 June 2011

Available online 7 July 2011

\section{Keywords:}

Uterine cancer

Racial

Disparity

Age

\section{A B S T R A C T}

Objective. We sought to determine whether racial disparities in tumor characteristics among uterine cancer patients persisted, and varied by age, in an equal-access healthcare population.

Methods. The distributions of tumor histology, stage and grade by race were compared for uterine cancers diagnosed from 1990 to 2003 using data from the U.S. Department of Defense's Automated Central Tumor Registry. Comparisons were conducted overall and stratified by age $(<50, \geq 50)$ using the Chi-square test.

Results. Of 2582 uterine tumors identified, 2057 (79.7\%) were diagnosed among White women and 183 (7.1\%) among Black women. Among all women analyzed, Blacks were more likely than Whites to present with non-endometrioid tumors ( $47.7 \%$ vs $23.5 \%, \mathrm{p}<0.01$ ), non-localized tumors ( $31.8 \%$ vs $24.5 \%, \mathrm{p}=0.02$ ), and poorly differentiated tumors $(20.5 \%$ vs $15.0 \%, \mathrm{p}<0.01)$. Among women 50 years and older, similar significant racial disparities were observed. However, no significant racial differences were observed among young patients. When comparisons were restricted to endometrioid histology adenocarcinomas, trends in age-specific disparities for older women were observed.

Conclusions. Our study suggests that racial disparities in uterine cancers persist between Blacks and Whites in an equal-access population. Blacks endure higher stage and grade tumors, and more aggressive histologies. This disparity in clinicopathologic factors is confined to women older than 50 years. Multiple factors such as racial variation in age-related health knowledge/behavior and estrogen metabolism may be related to the racial disparity. Published by Elsevier Inc

\section{Introduction}

Uterine corpus cancer is the most common gynecologic malignancy in the United States, accounting for approximately 6\% of all tumors diagnosed [1]. The vast majority of these tumors arise from the endometrium. The American Cancer Society estimated that 43,470 new cases of and 7950 deaths from endometrial cancer would occur during 2010 [1]. While uterine cancer incidence rates are lower among Black women than White women, [2] Blacks are more often diagnosed with aggressive histologic subtypes, advanced tumor stages, and/or higher tumor grades, and they suffer a correspondingly worse prognosis [2-21]. Indeed, the disease-specific mortality rate for Black women is nearly double that endured by White women [2].

\footnotetext{
The views expressed in this article are those of the authors and do not necessarily reflect the official policy or opinion of the Department of Defense or the United States Army or Navy, nor the US Government.

* Corresponding author.

E-mail address: john.farley@us.army.mil (J.H. Farley).
}

The etiology of the observed survival disparities between Black and White women likely is multi-factorial [5-7,10,12,13,15-17,20-27]. One of the often-cited explanations is racial variation in access to care $[5-7,12,13,22,23]$. With decreased access, Black women may see physicians less often or delay in seeking care, and thereby they may present at later stages or with more aggressive histologies $[6,7,10,12,13$, $22,23,28,29]$. Treatment differences, including inconsistencies in primary and adjuvant therapies, have also been implicated in the disparities in outcome and survival [7,9,12,13,15,17,22,23,26]. Multiple studies have evaluated contributions of various socioeconomic factors to endometrial cancer disparities, yet often they have been hampered by an inability to adequately control for confounding variables. Elucidation and clarification of any clinicopathologic disparities between Blacks and Whites could provide improved individualized treatments for endometrial cancer patients. The Department of Defense's (DoD) Military Health System provides a unique setting to investigate racial disparities because equal healthcare access is provided regardless of age, race, gender, or socioeconomic status [30].

Kost, et al. [30] previously evaluated clinicopathologic factors of endometrial cancer by race among DoD beneficiaries and found that 
White women presented with more favorable tumor stage, grade, and histologic types. The objective of the current study was to assess whether these previously described disparities between White and Black DoD beneficiaries persisted using the DoD-wide cancer registry data and whether the racial differences varied by age.

\section{Materials and methods}

After obtaining Institutional Review Board approval, uterine cancer data among DoD beneficiaries were extracted from the Automated Central Tumor Registry (ACTUR). Originating in 1986, ACTUR collects and tracks cancer data for DoD beneficiaries diagnosed or treated at military treatment facilities, including active-duty military personnel, retirees, and their dependents. Local tumor registrars, in direct consultation with corresponding gynecologic oncologists, abstract and enter data from a newly-diagnosed cancer patient's pertinent clinical history. Details regarding the tumor (e.g., site, histology and stage) and the patient (e.g., gender, race and age at diagnosis) then are forwarded for inclusion in the ACTUR database.

Clinical and pathologic data were extracted for all patients with invasive endometrial cancer included in the ACTUR database between 1990 and 2003. While all submitted data undergo verification, data prior to 1990 were excluded to minimize potential incomplete recording during the initial years of the cancer registry. Previously described methods [31] developed using national and state cancer registry guidelines $[32,33]$ were employed to identify and consolidate duplicate records. Abstracted variables included race, age at diagnosis, histology, grade, and stage. Patients were classified into groups: by age ( $<50$ years or $\geq 50$ years), and by race. Age was used as a proxy for menopausal/hormonal status. Various age thresholds for menopause have previously been employed in the literature. We selected a threshold of age 50 years in accordance with an investigation which revealed that, above this threshold, age-specific survival in endometrial cancer decreased significantly [34]. Race was determined by the primary gynecologic oncologist at the time of diagnosis or treatment using observation or beneficiary health record data, and was recorded in the respective local tumor registry.

Cases were categorized using the appropriate edition of the International Classification of Diseases for Oncology (ICD-0) [35-37]. The previous versions of ICD-O codes were converted to the third edition (ICD-O-3) by applying established guidelines. Uterine corpus cancers were defined using the primary site (topography) codes C540C543, C548-C549 and C559. Histology was defined using the ICD-O-3 morphology codes and classified as endometrioid [8380 (endometrioid adenocarcinoma), 8382 (endometrioid adenocarcinoma secretory variant), 8383 (endometrioid adenocarcinoma ciliary cell variant), 8140 (adenocarcinoma NOS)], non-endometrioid (all other known morphology), and unknown (9999). Central pathologic review of pathologic specimens was not performed.

Tumors were graded by extent of differentiation: well, moderately, poorly, undifferentiated, or unknown. One ambiguous case was excluded secondary to having a tumor grade designated as "B-cell," which suggested a non-uterine primary. Stage was categorized as local, regional, distant or unknown by combining Surveillance, Epidemiology and End Results (SEER) Summary Stage variables. Racial differences in the tumor characteristics were assessed using the Chi-square or Fisher's exact test for small sample sizes. The significance level was specified as $\mathrm{p}<0.05$. All calculations were performed using SAS Statistical Software, version 9.1 (SAS Institute, Inc., Cary, NC).

\section{Results}

Query of the ACTUR database revealed a total of 2582 eligible uterine tumors. There were 1924 (74.5\%) tumors of endometrioid histology and 655 (25.4\%) tumors of non-endometrioid histologic subtype, even though a central pathologic review and confirmation of histologic characteristics were not performed [Table 1]. Only 3 cases were designated as having unknown histology [Table 1]. Abstracted race designations included White, Black, Other, and Unknown. We restricted our analysis to the two racial categories which were specified discretely (White and Black). Of the 2582 tumors abstracted, 2057 (79.7\%) were diagnosed among White women and 183 (7.1\%) were diagnosed among Blacks [Table 1]. Forty-six tumors occurred in women on active duty, while the remaining tumors were diagnosed in retirees, dependents and family members [Table 1]. Given the small numbers of tumors in active duty women, we restricted our analysis to comparisons involving the non-active duty beneficiary population. Of the 2536 tumors in non-active duty beneficiaries, 2022 (79.7\%) were identified in White women and 176 (6.9\%) were identified in Blacks [Table 1].

Mean age at diagnosis in each of the age categories was similar for both Blacks and Whites. For young women ( $<50$ years), the mean age at diagnosis was 42.1 years for Whites and 40.8 years for Blacks $(p=0.23)$, while for older women ( $\geq 50$ years), the mean ages at diagnosis were 63.6 years and 63.0 years for Whites and Blacks, respectively $(p=0.43)$ [Table 2]. Similar results were noted when restricting the analysis to endometrioid histology [Table 2]. Not surprisingly, statistically significant distributions toward lower stage and grade favoring endometrioid histology were observed irrespective of age stratification (data not shown).

More Black women than White women were predisposed to nonendometrioid histology, (47.7\% vs $23.5 \%, \mathrm{p}<0.01$ ) [Table 3]. This relationship persisted when evaluating the older age group, with more Blacks than Whites older than 50 years presenting with non-

Table 1

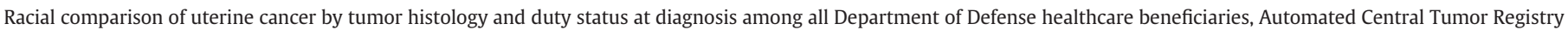
1990-2003.

\begin{tabular}{|c|c|c|c|c|c|c|c|c|c|c|c|}
\hline \multirow[t]{2}{*}{ Duty status } & \multirow[t]{2}{*}{ Histology } & \multicolumn{2}{|c|}{ White } & \multicolumn{2}{|c|}{ Black } & \multicolumn{2}{|c|}{ Other } & \multicolumn{2}{|c|}{ Unknown } & \multicolumn{2}{|l|}{ Total } \\
\hline & & $\mathrm{N}$ & $\%$ & $\mathrm{~N}$ & $\%$ & $\mathrm{~N}$ & $\%$ & $\mathrm{~N}$ & $\%$ & $\mathrm{~N}$ & $\%$ \\
\hline \multirow[t]{4}{*}{ Active duty } & Endometrioid & 26 & 74.3 & 6 & 85.7 & 2 & 100.0 & 0 & 0.0 & 34 & 73.9 \\
\hline & Non-endometrioid & 9 & 25.7 & 1 & 14.3 & 0 & 0.0 & 2 & 100.0 & 12 & 26.1 \\
\hline & Unknown & 0 & 0.0 & 0 & 0.0 & 0 & 0.0 & 0 & 0.0 & 0 & 0.0 \\
\hline & Total & 35 & & 7 & & 2 & & 2 & & 46 & \\
\hline \multirow[t]{4}{*}{ Non-active duty } & Endometrioid & 1545 & 76.4 & 92 & 52.3 & 197 & 74.1 & 56 & 77.8 & 1890 & 74.5 \\
\hline & Non-endometrioid & 475 & 23.5 & 84 & 47.7 & 69 & 25.9 & 15 & 20.8 & 643 & 25.4 \\
\hline & Unknown & $2^{\mathrm{a}}$ & 0.1 & 0 & 0.0 & 0 & 0.0 & 1 & 1.4 & $3^{a}$ & 0.1 \\
\hline & Total & 2022 & & 176 & & 266 & & 72 & & 2536 & \\
\hline \multirow[t]{4}{*}{ All beneficiaries } & Endometrioid & 1571 & 76.4 & 98 & 53.6 & 199 & 74.3 & 56 & 75.7 & 1924 & 74.5 \\
\hline & Non-endometrioid & 484 & 23.5 & 85 & 46.4 & 69 & 25.7 & 17 & 23.0 & 655 & 25.4 \\
\hline & Unknown & $2^{\mathrm{a}}$ & 0.1 & 0 & 0.0 & 0 & 0.0 & 1 & 1.4 & $3^{a}$ & 0.1 \\
\hline & Total & 2057 & & 183 & & 268 & & 74 & & 2582 & \\
\hline
\end{tabular}

\footnotetext{
a One case was excluded secondary to B-cell histology suggesting a non-uterine primary.
} 
Table 2

Observed age comparisons by age group and by race among non-active duty Department of Defense healthcare beneficiaries, Automated Central Tumor Registry, 1990-2003.

\begin{tabular}{|c|c|c|c|c|c|c|c|c|}
\hline \multirow[b]{2}{*}{ Histology } & \multirow[b]{2}{*}{ Age } & \multicolumn{3}{|c|}{ White } & \multicolumn{3}{|c|}{ Black } & \multirow[b]{2}{*}{$\mathrm{p}$-value ${ }^{\mathrm{b}}$} \\
\hline & & $\mathrm{N}$ & Mean & $\operatorname{Std}^{\mathrm{a}}$ & $\mathrm{N}$ & Mean & $\operatorname{Std}^{\mathrm{a}}$ & \\
\hline \multirow[t]{2}{*}{ All } & $<50$ & 370 & 42.1 & 0.32 & 36 & 40.8 & 1.20 & 0.23 \\
\hline & $\geq 50$ & 1652 & 63.6 & 0.20 & 140 & 63.0 & 0.67 & 0.43 \\
\hline \multirow[t]{2}{*}{ Endometrioid } & $<50$ & 270 & 42.9 & 0.34 & 22 & 40.8 & 1.43 & 0.10 \\
\hline & $\geq 50$ & 1275 & 63.3 & 0.23 & 70 & 63.4 & 0.84 & 0.94 \\
\hline
\end{tabular}

a Std Dev $=$ standard deviation

b Reported p-value from $t$-test.

endometrioid histology ( $50 \%$ vs $22.7 \%$, respectively, $\mathrm{p}<0.01$ ) [Table 3]. No such pattern was observed in young women [Table 3].

With respect to stage at diagnosis, more Whites than Blacks presented with localized disease $(75.6 \%$ vs $68.2 \%, \mathrm{p}=0.02$ ) [Table 3]. For women at least 50 years old, more White women were diagnosed with localized disease compared with Black women (75.1\% vs $65.7 \%$, $\mathrm{p}<0.01$ ), while no racial differences in stage at diagnosis were noted in young women [Table 3]. Similar results were observed when considering grade at diagnosis. White women, in general, more often presented with well-differentiated tumors $(45.2 \%$ vs $34.7 \%, \mathrm{p}<0.01$ )

\section{Table 3}

Racial comparison of uterine cancer by age, tumor histology, stage and grade at diagnosis among non-active duty Department of Defense healthcare beneficiaries, Automated Central Tumor Registry 1990-2003.

\begin{tabular}{|c|c|c|c|c|c|c|c|}
\hline \multirow{2}{*}{$\begin{array}{l}\text { Age at } \\
\text { diagnosis }\end{array}$} & \multicolumn{2}{|c|}{ Tumor characteristic } & \multicolumn{2}{|l|}{ White } & \multicolumn{2}{|c|}{ Black } & \multirow{2}{*}{$\begin{array}{l}\text { p value } \\
<0.01\end{array}$} \\
\hline & Histology & Endometrioid & 1545 & $76.4 \%$ & 92 & $52.3 \%$ & \\
\hline & & Non-endometrioid & 475 & $23.5 \%$ & 84 & $47.7 \%$ & \\
\hline & & Unknown & 2 & $0.1 \%$ & 0 & $0.0 \%$ & \\
\hline & Stage & Local & 1,528 & $75.6 \%$ & 120 & $68.2 \%$ & 0.02 \\
\hline & & Regional & 256 & $12.7 \%$ & 24 & $13.6 \%$ & \\
\hline & & Distant & 113 & $5.6 \%$ & 20 & $11.4 \%$ & \\
\hline & & Unknown & 125 & $6.2 \%$ & 12 & $6.8 \%$ & \\
\hline & Grade & Well differentiated & 913 & $45.2 \%$ & 61 & $34.7 \%$ & $<0.01$ \\
\hline & & $\begin{array}{l}\text { Moderately } \\
\text { differentiated }\end{array}$ & 518 & $25.6 \%$ & 31 & $17.6 \%$ & \\
\hline & & $\begin{array}{l}\text { Poorly } \\
\text { differentiated }\end{array}$ & 304 & $15.0 \%$ & 36 & $20.5 \%$ & \\
\hline & & Undifferentiated & 17 & $0.8 \%$ & 2 & $1.1 \%$ & \\
\hline & & Unknown & 270 & $13.4 \%$ & 46 & $26.1 \%$ & \\
\hline \multirow[t]{12}{*}{$<50$} & Histology & Endometrioid & 270 & $73.0 \%$ & 22 & $61.1 \%$ & 0.13 \\
\hline & & Non-endometrioid & 100 & $27.0 \%$ & 14 & $38.9 \%$ & \\
\hline & & Unknown & 0 & $0.0 \%$ & 0 & $0.0 \%$ & \\
\hline & Stage & Local & 288 & $77.8 \%$ & 28 & $77.8 \%$ & 0.95 \\
\hline & & Regional & 44 & $11.9 \%$ & 5 & $13.9 \%$ & \\
\hline & & Distant & 17 & $4.6 \%$ & 1 & $2.8 \%$ & \\
\hline & & Unknown & 21 & $5.7 \%$ & 2 & $5.6 \%$ & \\
\hline & Grade & Well differentiated & 189 & $51.1 \%$ & 20 & $55.6 \%$ & 0.14 \\
\hline & & $\begin{array}{l}\text { Moderately } \\
\text { differentiated }\end{array}$ & 84 & $22.7 \%$ & 3 & $8.3 \%$ & \\
\hline & & $\begin{array}{l}\text { Poorly } \\
\text { differentiated }\end{array}$ & 42 & $11.4 \%$ & 6 & $16.7 \%$ & \\
\hline & & Undifferentiated & 3 & $0.8 \%$ & 1 & $2.8 \%$ & \\
\hline & & Unknown & 52 & $14.1 \%$ & 6 & $16.7 \%$ & \\
\hline \multirow[t]{12}{*}{$\geq 50$} & Histology & Endometrioid & 1275 & $77.2 \%$ & 70 & $50.0 \%$ & $<0.01$ \\
\hline & & Non-endometrioid & 375 & $22.7 \%$ & 70 & $50.0 \%$ & \\
\hline & & Unknown & 2 & $0.1 \%$ & 0 & $0.0 \%$ & \\
\hline & Stage & Local & 1,240 & $75.1 \%$ & 92 & $65.7 \%$ & $<0.01$ \\
\hline & & Regional & 212 & $12.8 \%$ & 19 & $13.6 \%$ & \\
\hline & & Distant & 96 & $5.8 \%$ & 19 & $13.6 \%$ & \\
\hline & & Unknown & 104 & $6.3 \%$ & 10 & $7.1 \%$ & \\
\hline & Grade & Well differentiated & 724 & $43.8 \%$ & 41 & $29.3 \%$ & $<0.01$ \\
\hline & & $\begin{array}{l}\text { Moderately } \\
\text { differentiated }\end{array}$ & 434 & $26.3 \%$ & 28 & $20.0 \%$ & \\
\hline & & $\begin{array}{l}\text { Poorly } \\
\text { differentiated }\end{array}$ & 262 & $15.9 \%$ & 30 & $21.4 \%$ & \\
\hline & & Undifferentiated & 14 & $0.8 \%$ & 1 & $0.7 \%$ & \\
\hline & & Unknown & 218 & $13.2 \%$ & 40 & $28.6 \%$ & \\
\hline
\end{tabular}

a Chi-square or Fisher's exact p-value in comparison to Whites.
[Table 3]. No significant racial variations between young White and Black women were observed, yet Whites were more likely to be diagnosed with well-differentiated tumors than Blacks (43.8\% vs $29.3 \%$, $\mathrm{p}<0.01$ ) when women older than 50 years were evaluated [Table 3]. When comparisons were restricted to endometrioid histology, although there was a tendency for White women to have more favorable tumors, none of the racial differences were significant [Table 4]. However, among older women, the racial difference in tumor grade was borderline significant with more Blacks than Whites diagnosed with poorly differentiated tumors ( $20.0 \%$ vs $12.9 \%, p=0.06$ ) [Table 4 ].

\section{Discussion}

This study confirms that the often-cited racial disparity in clinicopathologic characteristics between Blacks and Whites [2-21] remains evident despite equal access to care. Moreover, we demonstrate that this racial variation is confined to older women, with Blacks prejudicially enduring non-endometrioid, non-localized, and poorly differentiated tumors. The data may suggest similar trends when considering endometrioid histologies alone.

Other investigators have attempted to evaluate the effect of socioeconomics on racial disparities. Hill, et al. [10] reported an analysis of data from the Black/White Cancer Survival Study (BWCSS). This study found that poverty index influenced grade at diagnosis. Yet, it necessarily was hampered by the drawbacks associated with any population-based evaluation, [38] as well as by selection biases arising both from exclusion of cases with incomplete interview records and from failure to capture grossly underserved patients. Barrett, et al. [6] also evaluated a cohort from the BWCSS; those results likewise were affected by the disadvantages hindering Hill, et al. [10]. Kost, et al. [30] evaluated an analogous DoD beneficiary population; however, our investigation expanded on both the population and goals considered in that study.

Table 4

Racial comparison of endometrioid histology by age, stage and grade at diagnosis among non-active duty Department of Defense healthcare beneficiaries, Automated Central Tumor Registry 1990-2003.

\begin{tabular}{|c|c|c|c|c|c|c|c|}
\hline \multirow{2}{*}{$\begin{array}{l}\text { Age at } \\
\text { diagnosis }\end{array}$} & \multicolumn{2}{|c|}{ Tumor characteristic } & \multicolumn{2}{|l|}{ White } & \multicolumn{2}{|c|}{ Black } & \multirow{2}{*}{$\begin{array}{l}\text { p-value }{ }^{a} \\
0.20\end{array}$} \\
\hline & Stage & Local & 1,211 & $78.4 \%$ & 67 & $72.8 \%$ & \\
\hline & & Regional & 181 & $11.7 \%$ & 10 & $10.9 \%$ & \\
\hline & & Distant & 57 & $3.7 \%$ & 7 & $7.6 \%$ & \\
\hline & & Unknown & 96 & $6.2 \%$ & 8 & $8.7 \%$ & \\
\hline & Grade & Well differentiated & 792 & $51.3 \%$ & 45 & $48.9 \%$ & 0.17 \\
\hline & & $\begin{array}{l}\text { Moderately } \\
\text { differentiated }\end{array}$ & 435 & $28.2 \%$ & 19 & $20.7 \%$ & \\
\hline & & Poorly differentiated & 192 & $12.4 \%$ & 17 & $18.5 \%$ & \\
\hline & & Undifferentiated & 4 & $0.3 \%$ & 0 & $0.0 \%$ & \\
\hline & & Unknown & 122 & $7.9 \%$ & 11 & $12.0 \%$ & \\
\hline \multirow[t]{9}{*}{$<50$} & Stage & Local & 224 & $83.0 \%$ & 16 & $72.7 \%$ & 0.34 \\
\hline & & Regional & 27 & $10.0 \%$ & 3 & $13.6 \%$ & \\
\hline & & Distant & 6 & $2.2 \%$ & 1 & $4.5 \%$ & \\
\hline & & Unknown & 13 & $4.8 \%$ & 2 & $9.1 \%$ & \\
\hline & Grade & Well differentiated & 155 & $57.4 \%$ & 17 & $77.3 \%$ & 0.22 \\
\hline & & $\begin{array}{l}\text { Moderately } \\
\text { differentiated }\end{array}$ & 68 & $25.2 \%$ & 2 & $9.1 \%$ & \\
\hline & & Poorly differentiated & 28 & $10.4 \%$ & 3 & $13.6 \%$ & \\
\hline & & Undifferentiated & 1 & $0.4 \%$ & 0 & $0.0 \%$ & \\
\hline & & Unknown & 18 & $6.7 \%$ & 0 & $0.0 \%$ & \\
\hline \multirow[t]{9}{*}{$\geq 50$} & Stage & Local & 987 & $77.4 \%$ & 51 & $72.9 \%$ & 0.23 \\
\hline & & Regional & 154 & $12.1 \%$ & 7 & $10.0 \%$ & \\
\hline & & Distant & 51 & $4.0 \%$ & 6 & $8.6 \%$ & \\
\hline & & Unknown & 83 & $6.5 \%$ & 6 & $8.6 \%$ & \\
\hline & Grade & Well differentiated & 637 & $50.0 \%$ & 28 & $40.0 \%$ & 0.06 \\
\hline & & $\begin{array}{l}\text { Moderately } \\
\text { differentiated }\end{array}$ & 367 & $28.8 \%$ & 17 & $24.3 \%$ & \\
\hline & & Poorly differentiated & 164 & $12.9 \%$ & 14 & $20.0 \%$ & \\
\hline & & Undifferentiated & 3 & $0.2 \%$ & 0 & $0.0 \%$ & \\
\hline & & Unknown & 104 & $8.2 \%$ & 11 & $15.7 \%$ & \\
\hline
\end{tabular}

a Chi-square or Fisher's exact p-value in comparison to Whites. 
Liu, et al. [12] addressed delay in presentation to care, finding no significant difference in time to presentation following the onset of vaginal bleeding between Blacks and Whites, yet simultaneously demonstrating persistent racial disparities in histology, stage and grade burdening Black women. While these results are provocative, the study included several drawbacks. In addition to involving only a small number (thirty-nine) of Black patients, the results were influenced by an undisclosed number of excluded patients who underwent radiation therapy alone due to severe medical conditions. This potentially introduced bias as Black patients have been shown to be disproportionately affected by poor overall health status [39]. Furthermore, while the investigation evaluated all patients meeting inclusion criteria at their institution, it made no comment regarding the uniformity of access to care for the hospital's catchment area.

The prognostic significance of age in endometrial cancer has been established previously, although the critical age is debatable $[3,5,9,11$, $16,20,34,40]$. Our stratification used 50 years old as a surrogate for menopausal status, based upon prior demonstration of a significant decrease in endometrial cancer survival after that threshold [34]. Thus, our results suggest that racial disparities in endometrial cancers are confined to postmenopausal Blacks when compared to Whites, and no such relationship exists for premenopausal women. Furthermore, when we excluded non-endometrioid histologies, a similar trend emerged, implying that the observed disparities may not be exclusively due to the preponderance of high-risk tumors in Blacks. This association with menopausal status may suggest variable estrogen exposure between racial groups, a mechanism that is particularly relevant in the absence of an intact hypothalamic-pituitary-ovarian axis.

The endometrium is hormonally sensitive, so it is not surprising that alterations in the hormonal milieu may contribute to carcinogenesis. The majority of endometrial cancers are diagnosed in the setting of estrogen excess in patients with risk factors for either unopposed endogenous or exogenous estrogen exposure. Tumors arising in this milieu are predominantly type I, or of endometrioid subtype $[40,41]$. Type II tumors, in contrast, are less common, demonstrate worse differentiation, and portend a less favorable prognosis [40,41]. Typically of uterine papillary serous or clear cell histologic subtype, type II tumors are thought to develop independent of estrogen exposure, arising instead in the setting of an atrophic endometrium [40,41]. Dedifferentiation from type I to type II may also occur [29].

Differential estrogen metabolism has long been implicated in development of hormonally-sensitive cancers $[5,6,10,16,41-43]$. Within the endometrium, estrogen induces transcriptional changes that cause downstream promotion of cell proliferation and inhibition of apoptosis [43-45]. In addition, depurinating adducts from estrogen's oxidative metabolites are believed to be carcinogenic [43]. Alterations in estrogen metabolism also have been implicated in oncogenesis through gene polymorphisms $[42,45,46]$. The cytochrome p450 enzyme CYP1B1, for example, has been linked to breast cancer development [45,47]. CYP1B1 upregulation is thought to instigate cellular damage by catalyzing the hydroxylation of estrogens, and it can disrupt cellular proliferation through interference with cell cycle regulation [29,45]. Polymorphisms of the CYP1B1 codons result in hyperactivation, and have been shown to impart increased incidence in endometrial cancer, $[45,46]$ though the findings have been conflicting $[42,46]$. In a separate pathway, estrogens bind to the estrogen receptor ligand binding domain, resulting in stimulation of cell proliferation in these target tissues [46]. Polymorphisms of estrogen receptor alpha likewise have been implicated in conferring increased risk of endometrial cancers in a recent pilot study by Sliwinski, et al [46]. Concurrent investigation into the seventransmembrane estrogen receptor GPR30, whose activation is known to promote endometrial proliferation, has highlighted a potential novel pathway for estrogen-mediated endometrial carcinogenesis [44].

Estrogen metabolism is an obvious focus for investigation into the etiology of the observed racial disparities in endometrial cancer. Indeed, racial variations in exogenous hormone use previously have been identified as contributors to differences in outcome between Blacks and Whites $[10,16,42]$. While unopposed exogenous estrogen serves as a risk factor for endometrial cancer development, the resulting tumors are typically of the more favorable type I biology and therefore are associated with better prognosis [10,40-42]. Estrogen replacement more often is prescribed to Whites than Blacks, in part perhaps, contributing to higher rates of type I tumors among Whites $[6,42]$. However, when controlling for exogenous hormone use, the observed disparities in rates of type I tumors remain, suggesting that other aspects of tumor biology also must be implicated [16]. Endogenous estrogen exposure has also been cited. Direct associations between the metabolic syndrome and its individual components and endometrial cancer risk have been previously described [48]. Brancati, et al. [39] reported that Blacks suffer a two-fold increased risk of diabetes when compared with Whites, even when controlling for the usual surrogates for obesity, BMI and waist-to-hip ratio. Related factors may account for the excess endometrial cancer risk we demonstrated in postmenopausal Black women.

The role of estrogen in racial disparities was highlighted in a retrospective analysis of Gynecologic Oncology Group (GOG) 137 data comparing recurrence-free and overall survival between Whites and Blacks receiving post-operative estrogen replacement therapy for surgically treated, early-stage endometrial cancer [16].While the Blacks on the treatment arm endured a relative risk of recurrence of 11.2 when compared with Whites, a similar relationship was not observed for the Blacks on the placebo arm [16]. The study concluded that Blacks may be at increased risk of recurrence when maintaining post-operative estrogen therapy and suggested that potential differences in estrogen metabolism could be a source of the racial variation [16].

Molecular alterations may contribute to differences in outcome between Blacks and Whites with endometrial cancer. An analysis of 147 patients diagnosed with endometrial cancer between 1995 and 2001 sought to analyze and compare the molecular profiles in endometrial cancer in White and Black patients using a number of known molecular markers [18]. Black patients had more type II carcinoma than White patients with high $\mathrm{p} 53$ protein expression increased significantly among the Black patients ( $49 \%$ vs. $30 \%, P=0.035$ ) versus White patients [18]. Studies have shown that p53 over-expression in endometrial cancer is associated with a more aggressive tumor characteristics and behavior including poor differentiation, deep myometrial invasion and lymph node metastases [15-18].

In another study 140 stage III/IV endometrial adenocarcinomas were screened for mutations in the PTEN gene [14]. Black women had cancers with significantly higher stage and grade that were more often nonendometrioid. PTEN mutation was seen in $14 \%$ cancers and was associated with endometrioid histology and more favorable survival. The frequency of PTEN mutations was significantly higher in Whites (22\% vs $5 \%, P=0.006$ ) [14]. This suggests that differences in the frequency of PTEN mutations contribute to the racial disparity in endometrial cancer survival.

One limitation of our study is the lack of uniformity in race reporting within the ACTUR database. While the primary gynecologic oncologist establishes the race designation forwarded to the registry, this provider typically ascertains the patient's race using the DoD's electronic beneficiary health record database. Race determination in this system is made upon enrollment as a military beneficiary, and arises from a combination of self- and administrative reporting. The balance of racial categories in ACTUR is determined through physician-reporting. As these race designations are unconfirmed, they may lead to misclassification that could attenuate the differences we reported between Blacks and Whites. Such attenuation could mask true differences in younger women or underestimate the differences observed in older women. Furthermore, the heterogeneous distribution of military treatment facilities may introduce selection bias in the patients reported to ACTUR, as remote patients are often referred for care in the civilian sector and therefore are not captured. This bias affects retired personnel and their dependents 
more significantly than active duty members. Given the small numbers of White [35] and Black [7] active duty patients, we focused on non-active duty beneficiaries and potentially introduced another source of bias.

Finally central pathologic review of all tissue and surgical specimens was not performed in this retrospective database review. This may bias those patients treated at academic centers, historically White patients, where specialized pathologists were available. Specialized pathologic review should allow more accurate diagnosis of advanced grade and poor prognosis histologic specimens. All patients included in this study were initially treated at medical centers with specialized pathologic review. Also, even among experts, reproducibility of endometrial cancer pathologic diagnosis can be suspect $[10,49]$. Evaluations of low grade and atypical hyperplastic lesions of the endometrium are notoriously poor $[10,49]$. Additionally, although FIGO grading has significant predictive value, the reproducibility of Grade 2 is limited such that a binary grading system has been proposed. Even with the binary system reproducibility among pathologists is poor and varies from only $80 \%$ to $85 \%$ [49].

Our study confirms that racial disparities in uterine cancers persist between Blacks and Whites in an equal access to care environment, suggesting that a significant proportion of the observed disparities cannot be attributed solely to unequal access to care. Furthermore, we found that older Black women carried the burden of the disparate tumor characteristics. Similar trends observed when considering endometrioid histology alone suggest that the disparities cannot be entirely attributed to racial differences histology. Further investigation into the nature of endometrial cancer disparity is warranted, particularly in order to confirm these results in other populations for which confounding factors (such as socioeconomics and access to care) are adequately controlled.

\section{Conflict of interest statement}

To the best of our knowledge, none of the authors has any relevant financial relationships or other conflicts of interest to report.

\section{References}

[1] American Cancer Society. Cancer facts \& figures. Atlanta: American Cancer Society; 2010.

[2] National Cancer Institute's Surveillance. Epidemiology and End Results Cancer Statistics SEER 17 data. [cited 2010 October]; Available from http://seer.cancer. gov/statfacts/html/corp.html2010.

[3] Clifford SL, Kaminetsky CP, Cirisano FD, Dodge R, Soper JT, Clarke-Pearson DL, et al. Racial disparity in overexpression of the p53 tumor suppressor gene in stage I endometrial cancer. Am J Obstet Gynecol Jun. 1997;176(6):S229-32.

[4] National Cancer Institute's Surveillance. Epidemiology and End Results SEER 9 data Fast Stats. [cited 2010 October]; Available from http://seer.cancer.gov/faststats/ selections.php 2010.

[5] Aziz H, Hussain F, Edelman S, Cirrone J, Aral I, Fruchter R, et al. Age and race as prognostic factors in endometrial carcinoma. Am J Clin Oncol Dec. 1996;19(6): 595-600.

[6] Barrett 2nd RJ, Harlan LC, Wesley MN, Hill HA, Chen VW, Clayton LA, et al. Endometrial cancer: stage at diagnosis and associated factors in black and white patients. Am J Obstet Gynecol Aug. 1995;173(2):414-22 discussion 22-3.

[7] Connell PP, Rotmensch J, Waggoner SE, Mundt AJ. Race and clinical outcome in endometrial carcinoma. Obstet Gynecol Nov. 1999;94(5 Pt 1):713-20.

[8] Cook LS, Kmet LM, Magliocco AM, Weiss NS. Endometrial cancer survival among U.S. black and white women by birth cohort. Epidemiology Jul. 2006;17(4):469-72.

[9] Hicks ML, Phillips JL, Parham G, Andrews N, Jones WB, Shingleton HM, et al. The National Cancer Data Base report on endometrial carcinoma in African-American women. Cancer Dec. 15 1998;83(12):2629-37.

[10] Hill HA, Coates RJ, Austin H, Correa P, Robboy SJ, Chen V, et al. Racial differences in tumor grade among women with endometrial cancer. Gynecol Oncol Feb. 1995;56(2): 154-63.

[11] Kosary CL. FIGO stage, histology, histologic grade, age and race as prognostic factors in determining survival for cancers of the female gynecological system: an analysis of 1973-87 SEER cases of cancers of the endometrium, cervix, ovary, vulva, and vagina. Semin Surg Oncol Jan-Feb. 1994;10(1):31-46.

[12] Liu JR, Conaway M, Rodriguez GC, Soper JT, Clarke-Pearson DL, Berchuck A Relationship between race and interval to treatment in endometrial cancer. Obstet Gynecol Oct. 1995;86(4 Pt 1):486-90.

[13] Madison T, Schottenfeld D, James SA, Schwartz AG, Gruber SB. Endometrial cancer: socioeconomic status and racial/ethnic differences in stage at diagnosis, treatment, and survival. Am J Public Health Dec. 2004;94(12):2104-11.
[14] Maxwell GL, Risinger JI, Hayes KA, Alvarez AA, Dodge RK, Barrett JC, et al. Racial disparity in the frequency of PTEN mutations, but not microsatellite instability, in advanced endometrial cancers. Clin Cancer Res Aug. 2000;6(8):2999-3005.

[15] Maxwell GL, Risinger JI. Racial disparities research: it's not just black and white. Gynecol Oncol May 2006;101(2):194-7.

[16] Maxwell GL, Tian C, Risinger JI, Hamilton CA, Barakat RR. Racial disparities in recurrence among patients with early-stage endometrial cancer: is recurrence increased in black patients who receive estrogen replacement therapy? Cancer Sep. 15 2008;113(6):1431-7.

[17] Randall TC, Armstrong K. Differences in treatment and outcome between AfricanAmerican and white women with endometrial cancer. J Clin Oncol Nov. 15 2003;21(22):4200-6.

[18] Schimp VL, Ali-Fehmi R, Solomon LA, Hammoud A, Pansare V, Morris RT, et al. The racial disparity in outcomes in endometrial cancer: could this be explained on a molecular level? Gynecol Oncol Sep. 2006;102(3):440-6.

[19] Setiawan VW, Pike MC, Kolonel LN, Nomura AM, Goodman MT, Henderson BE. Racial/ethnic differences in endometrial cancer risk: the multiethnic cohort study. Am J Epidemiol Feb. 1 2007;165(3):262-70.

[20] Steinhorn SC, Myers MH, Hankey BF, Pelham VF. Factors associated with survival differences between black women and white women with cancer of the uterine corpus. Am J Epidemiol Jul. 1986;124(1):85-93.

[21] Wright JD, Fiorelli J, Schiff PB, Burke WM, Kansler AL, Cohen CJ, et al. Racial disparities for uterine corpus tumors: changes in clinical characteristics and treatment over time. Cancer Mar. 15 2009;115(6):1276-85.

[22] Allard JE, Maxwell GL. Race disparities between black and white women in the incidence, treatment, and prognosis of endometrial cancer. Cancer Control Jan. 2009;16(1):53-6.

[23] Farley J, Risinger JI, Rose GS, Maxwell GL. Racial disparities in blacks with gynecologic cancers. Cancer Jul. 15 2007;110(2):234-43.

[24] Maxwell GL, Tian C, Risinger J, Brown CL, Rose GS, Thigpen JT, et al. Racial disparity in survival among patients with advanced/recurrent endometrial adenocarcinoma: a Gynecologic Oncology Group study. Cancer Nov. 1 2006;107(9):2197-205.

[25] Sherman ME, Carreon JD, Lacey Jr JV, Devesa SS. Impact of hysterectomy on endometrial carcinoma rates in the United States. J Natl Cancer Inst Nov. 16 2005;97(22):1700-2.

[26] Farley JH, Tian C, Rose GS, Brown CL, Birrer M, Risinger JI, et al. Chemotherapy intensity and toxicity among black and white women with advanced and recurrent endometrial cancer: a Gynecologic Oncology Group Study. Cancer Jan. 15 2010;116(2):355-61.

[27] Ferguson SE, Olshen AB, Levine DA, Viale A, Barakat RR, Boyd J. Molecular profiling of endometrial cancers from African-American and Caucasian women. Gynecol Oncol May 2006;101(2):209-13.

[28] Einstein MH, Kushner DM, Connor JP, Bohl AA, Best TJ, Evans MD, et al. A protocol of dual prophylaxis for venous thromboembolism prevention in gynecologic cancer patients. Obstet Gynecol Nov. 2008;112(5):1091-7.

[29] Arafa M, Somja J, Dehan P, Kridelka F, Goffin F, Boniver J, et al. Current concepts in the pathology and epigenetics of endometrial carcinoma. Pathology Dec. 2010;42(7): 613-7.

[30] Kost ER, Hall KL, Hines JF, Farley JH, Nycum LR, Rose GS, et al. Asian-Pacific Islander race independently predicts poor outcome in patients with endometrial cancer. Gynecol Oncol May 2003;89(2):218-26.

[31] Zhu K, Devesa SS, Wu H, Zahm SH, Jatoi I, Anderson WF, et al. Cancer incidence in the U.S. military population: comparison with rates from the SEER program. Cancer Epidemiol Biomarkers Prev Jun. 2009;18(6):1740-5 [Comparative Study: Research Support, N.I.H., Intramural; Research Support, Non-U.S. Gov't; Research Support, U.S. Gov't, Non-P.H.S.].

[32] Johnson CHPS, Adamo P, Fritz A, Percy-Laurry A, BK E. The multiple primary and histology coding rules. MD: National Cancer Institute Bethesda; 2007. 2007.

[33] The North American Association Of Central Cancer Registries. Report of the Automated Tumor Linkage work group of the ROC. Available from http://www. naaccr.org/index.asp?Col_SectionKey $=28 \&$ Col_ContentID $=433$ October 2005.

[34] Farley JH, Nycum LR, Birrer MJ, Park RC, Taylor RR. Age-specific survival of women with endometrioid adenocarcinoma of the uterus. Gynecol Oncol 2000 Oct;79(1): 86-9.

[35] World Health Organization, editor. International classification of diseases for oncology. Geneva: World Health Organization; 1976.

[36] Percy CV, Muir C. International classification of diseases for oncology. 2nd ed Geneva: World Health Organization; 1990.

[37] Fritz AJASK, et al. International classification of disease for oncology. 3rd ed. Geneva: World Health Organization; 2000.

[38] Oliver KE, Farley JH. Deciphering surveillance, epidemiology, and end results data analysis: are we seeing the whole picture? Cancer Mar. 82011 Epub ahead of print.

39] Brancati FL, Kao WH, Folsom AR, Watson RL, Szklo M. Incident type 2 diabetes mellitus in African American and white adults: the Atherosclerosis Risk in Communities Study. JAMA May 3 2000;283(17):2253-9.

[40] Felix AS, Weissfeld JL, Stone RA, Bowser R, Chivukula M, Edwards RP, et al. Factors associated with type i and type II endometrial cancer. Cancer Causes Control Nov. 2010;21(11):1851-6.

[41] Bokhman JV. Two pathogenetic types of endometrial carcinoma. Gynecol Oncol Feb. 1983;15(1):10-7.

[42] Rebbeck TR, Troxel AB, Wang Y, Walker AH, Panossian S, Gallagher S, et al Estrogen sulfation genes, hormone replacement therapy, and endometrial cancer risk. J Natl Cancer Inst Sep. 20 2006;98(18):1311-20.

[43] Zahid M, Kohli E, Saeed M, Rogan E, Cavalieri E. The greater reactivity of estradiol-3,4 quinone vs estradiol-2,3-quinone with DNA in the formation of depurinating 
adducts: implications for tumor-initiating activity. Chem Res Toxicol Jan 2006;19(1): 164-72.

[44] Lin BC, Suzawa M, Blind RD, Tobias SC, Bulun SE, Scanlan TS, et al. Stimulating the GPR30 estrogen receptor with a novel tamoxifen analogue activates SF-1 and promotes endometrial cell proliferation. Cancer Res Jul. 1 2009;69(13):5415-23.

[45] Saini S, Hirata H, Majid S, Dahiya R. Functional significance of cytochrome P450 $1 \mathrm{~B} 1$ in endometrial carcinogenesis. Cancer Res Sep. 1 2009;69(17):7038-45.

[46] Sliwinski T, Sitarek P, Stetkiewicz T, Sobczuk A, Blasiak J. Polymorphism of the ERalpha and CYP1B1 genes in endometrial cancer in a Polish subpopulation. J Obstet Gynaecol Res Apr. 2010;36(2):311-7.
[47] Bailey LR, Roodi N, Dupont WD, Parl FF. Association of cytochrome P450 1B1 (CYP1B1) polymorphism with steroid receptor status in breast cancer. Cancer Res Nov. 15 1998;58(22):5038-41.

[48] Rosato V, Zucchetto A, Bosetti C, Dal Maso L, Montella M, Pelucchi C, et al. Metabolic syndrome and endometrial cancer risk. Annals of oncology: official journal of the European Society for Medical Oncology/ESMO, 22(4); Apr. 2011. p. 884-9.

[49] Scholten AN, Smit VT, Beerman H, van Putten WL, Creutzberg CL. Prognostic significance and interobserver variability of histologic grading systems for endometrial carcinoma. Cancer Feb. 15 2004;100(4):764-72 [Comparative Study]. 